\title{
Erratum to: Urinary nerve growth factor correlates with the severity of urgency and pain: response to comments by Agilli et al.
}

\author{
Sang Woon Kim • Sang Hyun Jee • Soo Young Moon • \\ Ji Yu Kim • Jang Hwan Kim
}

Published online: 4 February 2015

(C) The International Urogynecological Association 2014

Erratum to: Int Urogynecol J

DOI 10.1007/s00192-014-2533-4

The title of this letter and the titles of references [1] and [2] were rendered incorrectly in the original publication. These errors are corrected here.

\section{References}

1. Agilli M, Aydin FN, Kurt YG, Cayci T (2014) Urinary nerve growth factor correlates with the severity of urgency and pain: methodological evaluation. Int Urogynecol J. doi:10.1007/s00192-014-2532-5

2. Kim SW, Im YJ, Choi HC, Kang HJ, Kim JY, Kim JH (2014) Urinary nerve growth factor correlates with the severity of urgency and pain. Int Urogynecol J 25(11):1561-1567. doi:10.1007/s00192-014-2424-8

The online version of the original article can be found at http://dx.doi.org/ 10.1007/s00192-014-2533-4.

S. W. Kim· S. H. Jee · S. Y. Moon · J. Y. Kim · J. H. Kim $(\bowtie)$ Department of Urology, Urological Science Institute, Yonsei

University College of Medicine, 50 Yonsei-ro, Seodaemun-gu,

Seoul 120-752, South Korea

e-mail: JKIM@yuhs.ac 